\title{
Análisis de fórmulas usuales y criterios hermenéuticos sobre dignidad de las personas privadas de libertad en la jurisprudencia de la Corte Interamericana de Derechos Humanos
}

\author{
Usual Formulas and Hermeneutical Criteria about Dignity of Prisoners in \\ the Inter-American Court of Human Rights
}

Florencia RATTI MENDAÑA ${ }^{1}$

Resumen: Se aborda la metodología que la Corte Interamericana de Derechos Humanos emplea para resolver casos en los que está en juego la dignidad de las personas privadas de libertad. Tal metodología consiste en el uso de fórmulas abstractas que se repiten a lo largo de las sentencias del tribunal y son aplicadas a modo de marco teórico para la evaluación de cada caso concreto. Se propone un análisis del contenido de cada fórmula, de su evolución a lo largo de la jurisprudencia de la Corte y del escenario fáctico subyacente.

Palabras clave: Dignidad, Detenidos, Corte Interamericana, Fórmulas

\begin{abstract}
This paper delves with the particular methodology the Inter-American Court uses to refer to prisoners' dignity. It explores the development of some general standards ("formulas") which the Court applies as a theoretical framework to each concrete case in order to determine whether there is a violation of human dignity or not. This practice inspires the study of the meaning of each formula, its evolution throughout the Court's case law and the underlying factual scenario.
\end{abstract}

\footnotetext{
${ }^{1}$ Doctora en Ciencias Jurídicas (Pontificia Universidad Católica Argentina). Profesora de Derecho Constitucional y Formación de l Pensamiento Jurídico-Político (Pontificia Universidad Católica Argentina). Becaria postdoctoral del Consejo Nacional de Investigaciones Científicas y Técnicas (CONICET). Correo electrónico: florenciaratti@uca.edu.ar El presente estudio se enmarca en los siguientes proyectos de investigación: PICTO 0032-2017 "El concepto de dignidad humana según la Corte Interamericana de Derechos Humanos. Análisis de los casos contenciosos y de las opiniones consultivas" (cofinanciado por la Facultad de Derecho de la Pontificia Universidad Católica Argentina y ANPCyT) y IUS (UCA) 80020190100018CT: "El precedente judicial en América Latina: análisis comparado".
} 
Keywords: Dignity, Prisoners, Inter-American Court, Formulas

\section{Introducción}

El discurso de la Corte Interamericana de Derechos Humanos (Corte IDH) sobre dignidad de los detenidos surge de la interpretación y aplicación del artículo 5.2 de la Convención Americana sobre Derechos Humanos (CADH). Allí se establece que "Toda persona privada de libertad será tratada con el respeto debido a la dignidad inherente al ser humano".

En otro lugar examiné aquel discurso y arribé a la conclusión de que el tribunal ha creado una serie de fórmulas que invoca repetidamente en sus decisiones sobre la materia ${ }^{2}$. Este trabajo se presenta como una profundización de aquel descubrimiento: aquí se estudiará separadamente cada una de esas fórmulas a fin de (i) analizar su contenido y los criterios interpretativos que de ellas surgen y (ii) estudiar cómo se plasma la repetición de fórmulas en el discurso de la Corte IDH.

Se propenderá al cumplimiento de tales objetivos a través del cotejo tanto de las fórmulas como del escenario fáctico típico al que se refieren y de los subescenarios que la Corte IDH ha ido delineando. Asimismo, se estudiará el patrón de invocación de estas fórmulas por parte del tribunal, con el fin de explicitar qué sentencias elige citar la Corte cada vez que las emplea. Finalmente, se evidenciará el uso que hace de ellas como marco teórico a partir del cual evalúa los hechos relevantes de cada caso concreto.

Se parte de la hipótesis de que las fórmulas utilizadas por la Corte IDH constituyen criterios o estándares argumentativos que el tribunal aplica cada vez que se enfrenta a determinados escenarios fácticos, a fin de evaluar si ha habido o no una vulneración concreta de la CADH.

La metodología utilizada es la dogmática jurisprudencial, con estudio y análisis de datos. El abordaje propuesto, consistente en la identificación de fórmulas desarrolladas por el tribunal es, en cierta medida, inexplorado: no solo se analizarán criterios interpretativos de la Corte sobre

\footnotetext{
${ }^{2}$ Ratti (2021).
} 
un tópico determinado, sino que se explicitará un modo típico de sentenciar, de argumentar y de utilizar su propio cuerpo jurisprudencial.

A la fecha, existen diversos análisis de los estándares de la Corte sobre personas privadas de libertad, pero pocos se detienen en el discurso del tribunal sobre la dignidad de aquel grupo humano3 . Por lo demás, a pesar de que algunas de las fórmulas que aquí se presentan ya han sido identificadas como estándares ${ }^{4}$, nunca se ha elaborado, hasta ahora, una reconstrucción jurisprudencial completa de cada una de ellas.

En consecuencia, el estudio sistematizado de las fórmulas facilitará una esquematización de los principales criterios hermenéuticos sobre vulneración de la dignidad de personas privadas de libertad en la jurisprudencia interamericana. Esto no solo tornará visibles los estándares que promueven el respeto por la dignidad de los detenidos ${ }^{5}$, sino también reducirá, en tal ámbito, el espectro de ambigüedad, ambivalencia e indefinición que rodea al término "dignidad"6.

\section{Las fórmulas sobre dignidad de los detenidos. Sentencias fundacionales y evolución}

A continuación, se presentarán las fórmulas usuales sobre dignidad de personas privadas de libertad en la jurisprudencia de la Corte IDH. Se identificará, para cada una de ellas, su sentencia fundacional y se reconstruirá la línea jurisprudencial a partir de la enumeración de sentencias en las que cada fórmula se repite 7.

La sentencia fundacional o fundadora de línea ha sido definida como aquella que por primera vez examina un determinado patrón fáctico ${ }^{8}$. Aquí se utilizará el concepto, no obstante, para identificar aquella sentencia en la que por primera vez la Corte enuncia lo que se irá

\footnotetext{
${ }^{3}$ Sí lo hace el estudio de Girón (2018), aunque solo analiza cinco sentencias de la Corte IDH. Por otra parte, hay estudios referidos a la dignidad en general en la jurisprudencia de la Corte IDH, que abarcan, entre otros, los casos de personas privadas de libertad Amezcúa (2007); Bohórquez, Aguirre (2009). El propio cuadernillo de la Corte IDH (2020) sobre personas privadas de libertad también constituye un aporte significativo.

${ }^{4}$ Castro, Cillero y Mera (2010) y Castro (2018).

${ }^{5}$ La Relatoría de Personas Privadas de Libertad de la Comisión Interamericana de Derechos Humanos expresamente solicitó a la academia que colaborásemos con ese objetivo Escobar (2013), p. 53.

${ }^{6}$ Bohórquez; Aguirre (2009), pp. 41-42 y 58; Glendon (2012), esp. pp. 259-260.

${ }^{7}$ Por una cuestión de espacio la cita de sentencias de la Corte IDH se abreviará con el nombre de una de las partes y, entre paréntesis, el número de serie de cada sentencia. A su vez, se indicará expresamente a qué párrafo de la sentencia se hace referencia. En el acápite "Jurisprudencia citada", al final de este trabajo, se encontrarán las citas completas de todas las sentencias mencionadas en el texto.

${ }^{8}$ López (2006), p. 114.
} 
convirtiendo, a lo largo del desarrollo jurisprudencial, en las fórmulas usuales sobre dignidad de personas privadas de libertad.

La reconstrucción de las cadenas de citas que aquí se despliega parte del concepto de "sentencia arquimédica" desarrollado por López Medina para el estudio de líneas jurisprudenciales ${ }^{9}$. Se trata de aquella sentencia a partir de la cual "el investigador tratará de desenredar las relaciones estructurales entre varias sentencias"10. Para este análisis, se tomó como "sentencia arquimédica" la última sentencia sobre personas privadas de libertad del año 2018: el caso Chinchilla Sandoval11. Se aplicó entonces la "ingeniería reversa"12, consistente en ir hacia atrás en busca de sentencias citadas en la sentencia arquimédica e identificar en ellas citas de otras sentencias, hasta llegar a tener un amplio campo de decisiones judiciales que se invocan entre sí. De ese modo es posible explicitar en qué decisiones judiciales aparece cada fórmula y qué sentencias cita la Corte cuando la invoca.

Cabe destacar que la Corte no utiliza exactamente las mismas palabras cada vez que aplica una fórmula o estándar. Si bien generalmente lo hace, hay casos en los que algunos términos son reemplazados por sinónimos o bien la Corte altera su orden. En otros casos, la fórmula atraviesa una evolución en el discurso de la Corte, que provoca alteraciones en su contenido (aunque no en su esencia). En definitiva, debe tenerse presente que, en ocasiones, la fórmula varía mínimamente en su redacción. Por eso, al transcribir las fórmulas en este trabajo no se colocan entre comillas ni se hace referencia a una "fórmula literal", sino a fórmulas habituales o usuales. De cualquier modo, se ha procurado hallar una redacción que refleje lo más fielmente posible la esencia de cada fórmula, a fin de uniformarla y dejar de lado las diferenciaciones menores que pueden darse en cada sentencia. Asimismo, si una fórmula hubiera sufrido modificaciones relevantes a lo largo de la jurisprudencia de la Corte IDH, ello se señalará oportunamente.

\subsection{CONDICIONES DE DETENCIÓN}

Fórmula: En los términos del artículo 5.2 de la Convención toda persona privada de libertad tiene derecho a vivir en condiciones de detención compatibles con su dignidad personal y el Estado debe garantizarle el derecho a la vida y a la integridad personal.

\footnotetext{
${ }^{9}$ López (2006).

${ }^{10}$ López (2006), p. 132.

${ }^{11}$ Corte IDH, Caso Chinchilla Sandoval vs. Guatemala, Serie C № 312, sentencia de 29 de febrero 2016. Más allá de que la línea de corte se encuentra, en principio, en el año 2018, haré algunas referencias ocasionales a sentencias posteriores de la Corte IDH, a las que accedí gracias al Cuadernillo de Jurisprudencia sobre personas privadas de libertad Corte IDH (2020).

12 López (2006), p. 170 y ss.
} 
Mediante esta fórmula, la Corte extrae del deber de tratar con respeto a la dignidad a toda persona privada de la libertad - previsto en el texto de la $\mathrm{CADH}$ - un derecho a vivir en condiciones de detención compatibles con tal dignidad. A su vez, suele desprender de allí el deber del Estado de garantizar el derecho a la vida, a la integridad personal, a la salud y a un estado de bienestar.

Aparece — con algunas variaciones, que serán explicitadas más adelante- en Neira Alegría; Castillo Petruzzi; Cantoral Benavídez; Bámaca Velázquez; Bulacio; Instituto de Reeducación del Menor; Tibi; De la Cruz Flores; Lori Berenson Mejía; Caesar; Fermín Ramírez; Raxcacó Reyes; García Asto; López Álvarez; Montero Aranguren; Caso del Penal Miguel Castro; Boyce; Chaparro Álvarez; Yvon Neptune; Vélez Loor; Vera Vera; Fleury; Pacheco Teruel; Díaz Peña; Espinoza González; Quispialaya Vilcapoma; Chincilla Sandoval; Hernández ${ }^{13}$.

No fue posible llegar, a través de la ingeniería de reversa, a los casos Fleury y Mendoza, pues no son citados al momento de invocar la fórmula en las sentencias subsiguientes. Sin embargo, pude constatar, a través del cuadernillo de jurisprudencia sobre personas privadas de libertad recientemente publicado por la Corte ${ }^{14}$, que la fórmula también se invoca en aquellas dos sentencias.

Se trata de la fórmula que más se repite en el discurso del tribunal. Su sentencia fundacional es Neira Alegría, oportunidad en que la Corte emplea la frase por primera vez y, por ese motivo, no cita nada cuando la enuncia. Pero en la sentencia inmediatamente posterior sobre personas

\footnotetext{
${ }^{13}$ Corte IDH, Caso Neira Alegría y otros vs. Perú, Serie C № 20, sentencia de 19 de enero de 1995, párr. 60; Corte IDH, Caso Castillo Petruzzi y otros vs. Perú, Serie C № 52, sentencia de 30 de mayo de 1999, párr. 195; Corte IDH, Caso Cantoral Benavídez vs. Perú, Serie C № 69, sentencia de 18 de agosto de 2000, párr. 87; Corte IDH, Caso Bámaca Velázquez vs. Guatemala, Serie C № 70, Sentencia de 25 de noviembre de 2000, párr. 171; Corte IDH, Caso Bulacio vs. Argentina, Serie C № 100, sentencia de 18 de septiembre de 2003, párr. 126; Corte IDH, Caso Instituto de Reeducación del Menor vs. Paraguay, Serie C № 112, sentencia de 2 de septiembre de 2004, párr. 151; Corte IDH, Caso Tibi vs. Ecuador, Serie C № 114, sentencia de 7 de septiembre de 2004, párr. 150; Corte IDH, Caso De la Cruz Flores vs. Perú, Serie C № 115, sentencia de 18 de noviembre de 2004, párr. 124; Corte IDH, Caso Lori Berenson Mejía vs. Perú, Serie C № 119, sentencia de 25 de noviembre de 2004, párr. 102; Corte IDH, Caso Caesar vs. Trinidad y Tobago, Serie C № 123, sentencia de 11 de marzo de 2005, párr. 96; Corte IDH, Caso Fermín Ramírez vs. Guatemala, Serie C № 126, párr. 118; Corte IDH, Caso Raxcacó Reyes vs. Guatemala, Serie C № 133, sentencia de 15 de septiembre de 2005, párr. 95; Corte IDH, Caso García Asto y Ramírez Rojas vs. Perú, Serie C № 137, sentencia de 25 de noviembre de 2005, párr. 221; Corte IDH, Caso López Álvarez vs. Honduras, Serie C № 141, sentencia de 1 de febrero de 2006, párr. 105; Corte IDH, Caso Montero Aranguren y otros (Retén de Catia) vs. Venezuela, Serie C № 150, sentencia de 5 de julio de 2006, párr. 146; Corte IDH, Caso del Penal Miguel Castro Castro Vs. Perú, Serie C № 160, sentencia de 25 de noviembre de 2006, párr. 315; Corte IDH, Caso Boyce y otros vs. Barbados, Serie C № 169, sentencia de 20 de noviembre de 2007, párr. 88; Corte IDH, Caso Chaparro Álvarez y Lapo Íñiguez vs. Ecuador, Serie C № 170, sentencia de 21 de noviembre de 2007, párr. 170; Corte IDH, Caso Yvon Neptune vs. Haití, Serie C № 180, sentencia 6 mayo de 2008, párr. 130; Corte IDH, Caso Vélez Loor vs. Panamá, Serie C № 218, sentencia 23 de noviembre de 2010, párr. 198; Corte IDH, Caso Vera Vera y otra vs. Ecuador, Serie C № 226, sentencia de 19 de mayo de 2011, párr. 42; Corte IDH, Caso Fleury y otros vs. Haití, Serie C № 236, sentencia 23 de noviembre de 2011, párr. 83; Corte IDH, Caso Pacheco Teruel y otros vs. Honduras, Serie C № 241, sentencia de 27 de abril de 2012, párr. 63; Corte IDH, Caso Díaz Peña vs. Venezuela, Serie C № 244, sentencia de 26 de junio de 2012, párr. 135; Corte IDH, Caso Espinoza González vs. Perú, Serie C № 289, sentencia de 20 de noviembre de 2014, párr. 205; Corte IDH, Caso Quispialaya Vilcapoma vs. Perú, Serie C № 308, sentencia de 23 de noviembre de 2015, párr. 117; Corte IDH, Caso Chincilla Sandoval vs. Guatemala, Serie C № 312, sentencia de 29 de febrero 2016, párr. 169; Corte IDH, Caso Vicky Hernández y otras vs. Honduras, Serie C № 395, sentencia de 26 de marzo de 2021, párr. 56.

${ }^{14}$ Corte IDH (2020).
} 
privadas de libertad - el caso Castillo Petruzzi-, la Corte invoca la expresión y cita, en nota al pie, el caso Neira Alegría.

La fórmula va variando paulatinamente en algunos aspectos de su estructura. Desde Neira Alegría hasta Instituto de Reeducación del Menor, aparece tal y como está redactada más arriba. No obstante, en el caso Tibi, la Corte reduce la fórmula y abandona la referencia a los derechos a la vida y a la integridad personal. Esta referencia específica reaparecerá en algunos casos aislados, como Raxcacó Reyes, Espinoza González y Quispialaya Vilcapoma. Y, en López Álvarez, únicamente se mencionará la integridad personal. Esto muestra que en el empleo de las fórmulas subyace un concepto general común — las condiciones dignas de detención- que se presenta acompañado de elementos aleatorios - ciertos derechos concretos que en consecuencia debe proteger el Estado-.

Finalmente, la Corte desarrolla, con el paso del tiempo (especialmente, a partir del caso Boyce), una nueva versión de esta fórmula en la que reemplaza la referencia a la vida y a la integridad personal por la de la salud y el bienestar. Se analizará, a continuación, cómo aparece esta reformulación en Chinchilla Sandoval:

En consecuencia, de conformidad con el artículo 5.1 y 5.2 de la Convención, toda persona privada de libertad tiene derecho a vivir en condiciones de detención compatibles con su dignidad personal. Esto implica el deber del Estado de salvaguardar la salud y el bienestar de las personas privadas de libertad y de garantizar que la manera y el método de privación de libertad no excedan el nivel inevitable de sufrimiento inherente a la misma.

A nota al pie, se citan los casos Instituto de Reeducación del Menor vs. Paraguay, Quispialaya Vilcapoma vs. Perú y una sentencia del TEDH: Kudla vs. Poland ${ }^{15}$. Sin embargo, no se invocan las otras tantas sentencias que contienen la fórmula. Por lo demás, en Instituto de Reeducación del Menor, la fórmula no aparecía tal como se la invoca en Chinchilla Sandoval, sino que su enunciado era idéntico al de la sentencia fundacional (Neira Alegría). Además, el caso no versaba sobre un detenido en un establecimiento carcelario, sino sobre un adolescente institucionalizado en un centro para menores. Quispialaya Vilcapoma - el otro precedente citado- tampoco se refería a una persona privada de libertad en un establecimiento carcelario, sino a un recluta enlistado voluntariamente en el servicio militar de Perú; la fórmula aparecía allí, pues la Corte IDH la había aplicado en el entendimiento de que cabía asimilar la situación, por el deber de seguridad que recaía, en ambos casos, sobre el Estado. No hay justificación, por ende, para la invocación de esos dos precedentes en Chinchilla Sandoval, que efectivamente giraba en torno al escenario fáctico

15 TEDH, № 30210/96, párr. 93-94, ECHR 2000-XI. 
típico: una reclusa que no había recibido tratamiento adecuado para su diabetes en el establecimiento carcelario. Si el nexo analógico que pretendía establecer la Corte IDH era el de la protección de la salud de las personas que están bajo su custodia por parte del Estado, la Corte pudo haber utilizado precedentes más similares al escenario fáctico de Chinchilla Sandoval, en los que no se hubiera prestado la adecuada atención médica dentro de la cárcel.

En el caso De la Cruz Flores ${ }^{16}$ también aparece la fórmula en aquella nueva versión, pero como cita textual de la sentencia del TEDH. Así, en el párrafo 134 dice la Corte IDH:

Por su parte, la Corte Europea ha sostenido que

Según [el artículo 3 de la Convención], el Estado debe asegurar que una persona esté detenida en condiciones que sean compatibles con el respeto a su dignidad humana, que la manera y el método de ejercer la medida no le someta a angustia o dificultad que exceda el nivel inevitable de sufrimiento intrínseco a la detención, y que, dadas las exigencias prácticas del encarcelamiento, su salud y bienestar estén aseguradas adecuadamente, brindándole, entre otras cosas, la asistencia médica requerida.

A nota al pie se invoca la sentencia del TEDH Kudla v. Poland. Es evidente que fue justamente esa decisión del tribunal regional europeo la causa de modificación de la fórmula por parte de la Corte IDH, aunque, como se vio en Chinchilla Sandoval, la Corte no siempre fue clara al explicitar esa influencia ${ }^{17}$.

\subsection{ESTADO GARANTE}

Fórmula: El Estado, como responsable de los establecimientos de detención, es el garante de los derechos de los detenidos.

Las fórmulas "condiciones de detención" y "Estado garante" comenzaron siendo una, pero luego se escindieron en oraciones independientes, con sus respectivas citas. Esta escisión carece de sentido, por cuanto redunda en dos notas al pie prácticamente idénticas ${ }^{18}$. En la actualidad, la Corte las invoca, aleatoriamente, juntas o separadas; de allí que se enumere aquí como

\footnotetext{
${ }^{16}$ Corte IDH, Caso De La Cruz Flores vs. Perú, Serie C № 115, Sentencia de 18 de noviembre de 2004.

${ }_{17}$ Para un análisis detallado del modo y las razones por las cuales los discursos judiciales de los tribunales regionales se inspiran entre sí en materia de dignidad: McCrudden (2008), en especial, p. 694 y ss.; Carozza (2003), p. 1081.

${ }^{18}$ Por ejemplo, en los casos Corte IDH, Caso De La Cruz Flores vs. Perú, Serie C № 115, Sentencia de 18 de noviembre de 2004; Corte IDH, Cao Lori Berenson Mejía vs. Perú, Serie C № 119, sentencia de 25 de noviembre de 2004, se citan los mismos tres casos para las dos fórmulas: Corte IDH, Caso Tibi vs. Ecuador, Serie C № 114, sentencia de 7 de septiembre de 2004; Corte IDH, Caso Instituto de Reeducación del Menor vs. Paraguay, Serie C № 112, sentencia de 2 de septiembre de 2004 y Corte IDH, Caso Bulacio vs. Argentina, Serie C № 100, sentencia de 18 de septiembre de 2003. La única diferencia en la cita reside en que, en de Instituto de Reeducación, se invoca el párrafo 152 en lugar del 151.
} 
fórmula, a pesar de que no contiene expresamente el sustantivo "dignidad" ni su forma adjetivada.

Esta fórmula se conecta con -y generalmente viene acompañada de-aquella que indica que los detenidos tienen una relación de especial sujeción con el Estado, debido a que se encuentran bajo su custodia.

En definitiva, lo que intenta señalar la Corte es que el Estado, en cuanto dueño y custodio de los establecimientos carcelarios, es responsable de la vida, integridad personal, salud y bienestar de los detenidos que allí se encuentran. En virtud de ello, no puede delegar la administración de algunos aspectos de la prisión en los internos y debe evitar modelos en que algunos internos puedan tener poder sobre otros ${ }^{19}$.

El reconocimiento del Estado como garante de los establecimientos de detención le ha permitido a la Corte IDH responsabilizarlo por todo lo que allí sucede; es decir, por todo daño que sufre una persona privada de libertad, sea que provenga de un agente penitenciario, de otro interno o de un tercero. En el primer caso se reconoce responsabilidad por acción y en los demás, por omisión, al no haber cumplido el deber de prevención tendiente a evitar situaciones de violencia en el establecimiento.

A partir de esta fórmula se desprenden, entonces, diversos deberes a cargo del Estado y la posibilidad de incurrir en responsabilidad internacional ${ }^{20}$. Esta hermenéutica también sustenta la fórmula según la cual el Estado tiene a su cargo la prueba de que el deterioro en la salud del detenido no es su responsabilidad 21 .

Concretamente, la fórmula "Estado garante" se encuentra en las siguientes sentencias: Neira Alegría; Castillo Petruzzi; Cantoral Benavídez; Bámaca Velázquez; Hilaire Constantine; Bulacio; Instituto de Reeducación del Menor; Tibi; De la Cruz Flores; Lori Berenson; Caesar; Fermín Ramírez; Raxcacó Reyes; García Asto; López Álvarez; Montero Aranguren; Caso del Penal Miguel

\footnotetext{
${ }^{19}$ Escobar (2013), p. 49.

${ }^{20}$ Para un análisis de las obligaciones del Estado por su deber de custodia, véase Acosta-López; Amaya-Villarreal (2011), en esp. pp. 306 y ss.

${ }^{21}$ Cfr. Corte IDH, Caso "Niños de la Calle" (Villagrán Morales y otros) vs. Guatemala, Serie C № 63, sentencia de 19 de noviembre 1999 párrs. 95 y 170; Corte IDH, Caso Juan Humberto Sánchez vs. Honduras, Serie C № 99, sentencia de 7 de junio de 2003, párrs. 100 y 111; Mendoza (C260, párr. 203) y Isaza Uribe (C363, párr. 88).
} 
Castro; Chaparro Álvarez; Yvon Neptune; Vélez Loor; Vera Vera; Fleury; Pacheco Teruel; Díaz Peña; Espinoza González; Quispialaya Vilcapoma; Chinchilla Sandoval; Hernández vs. Argentina ${ }^{22}$.

\subsection{VIDA DIGNA}

Fórmula: El Estado debe garantizar a los reclusos la existencia de condiciones que respeten sus derechos fundamentales y una vida digna.

La Corte utiliza esta fórmula en Instituto de Reeducación del Menor, Lori Berenson, García Asto, Yvón Neptune y Pacheco Teruel ${ }^{23}$. Como resulta evidente, es una enunciación muy similar a lo que la Corte indica, otras veces, a través de las fórmulas "condiciones de detención" y "Estado garante", solo que mientras que allí alude a la dignidad y a su relación con el derecho a la vida, aquí introduce, específicamente, la expresión "vida digna"24. Al invocarla, suele mencionar en nota al pie las “Reglas Mínimas de Naciones Unidas para el Tratamiento de Reclusos”.

No obstante, la diferenciación en los términos parece no tener demasiada relevancia para la Corte: en García Asto, cita a nota al pie el caso Raxcacó Reyes, en su párrafo 95, pero, en esta última sentencia, la Corte no había utilizado exactamente la fórmula "vida digna", sino que había sostenido que "el Estado debe garantizar el derecho a la vida y a la integridad personal de los

\footnotetext{
22 Corte IDH, Caso Neira Alegría y otros vs. Perú, Serie C № 20, sentencia de 19 de enero de 1995, párr. 60; Corte IDH, Caso Castillo Petruzzi y otros vs. Perú, Serie C № 52, sentencia de 30 de mayo de 1999, párr. 195; Corte IDH, Caso Cantoral Benavídez vs. Perú, Serie C № 69, sentencia de 18 de agosto de 2000, párr. 87; Corte IDH, Caso Bámaca Velázquez vs. Guatemala, Serie C № 70, Sentencia de 25 de noviembre de 2000, párr. 171; Corte IDH, Caso Hilaire Constantine y Benjamin et al. vs. Trinidad and Tobago, Serie C № 94 sentencia 21 de junio de 2002, párr. 165 ; Corte IDH, Caso Bulacio vs. Argentina, Serie C № 100, sentencia de 18 de septiembre de 2003, párr. 126; Corte IDH, Caso Instituto de Reeducación del Menor vs. Paraguay, Serie C № 112, sentencia de 2 de septiembre de 2004, párr. 159; Corte IDH, Caso Tibi vs. Ecuador, Serie C № 114, sentencia de 7 de septiembre de 2004, párr. 262; Corte IDH, Caso De la Cruz Flores vs. Perú, Serie C № 115, sentencia de 18 de noviembre de 2004, párr. 124; Corte IDH, Caso Lori Berenson Mejía vs. Perú, Serie C № 119, sentencia de 25 de noviembre de 2004, párr. 102; Corte IDH, Caso Caesar vs. Trinidad y Tobago, Serie C № 123, sentencia de 11 de marzo de 2005, párr. 97; Corte IDH, Caso Fermín Ramírez vs. Guatemala, Serie C № 126, párr. 118; Corte IDH, Caso Raxcacó Reyes vs. Guatemala, Serie C № 133, sentencia de 15 de septiembre de 2005, párr. 95; Corte IDH, Caso García Asto y Ramírez Rojas vs. Perú, Serie C № 137, sentencia de 25 de noviembre de 2005, párr. 221; Corte IDH, Caso López Álvarez vs. Honduras, Serie C № 141, sentencia de 1 de febrero de 2006, párr. 106; Corte IDH, Caso Montero Aranguren y otros (Retén de Catia) vs. Venezuela, Serie C № 150, sentencia de 5 de julio de 2006, párr. 87; Corte IDH, Caso del Penal Miguel Castro Castro vs. Perú, Serie C № 160, sentencia de 25 de noviembre de 2006, párr. 315; Corte IDH, Caso Chaparro Álvarez y Lapo Íñiguez vs. Ecuador, Serie C № 170, sentencia de 21 de noviembre de 2007, párr. 170; Corte IDH, Caso Yvon Neptune vs. Haití, Serie C № 180, sentencia 6 mayo de 2008, párr. 130; Corte IDH, Caso Vélez Loor vs. Panamá, Serie C № 218, sentencia 23 de noviembre de 2010, párr. 198; Corte IDH, Caso Vera Vera y otra vs. Ecuador, Serie C № 226, sentencia de 19 de mayo de 2011, párr. 42; Corte IDH, Caso Fleury y otros vs. Haití, Serie C № 236, sentencia 23 de noviembre de 2011, párr. 84; Corte IDH, Caso Pacheco Teruel y otros vs. Honduras, Serie C № 241, sentencia de 27 de abril de 2012, párr. 63; Corte IDH, Caso Díaz Peña vs. Venezuela, Serie C № 244, sentencia de 26 de junio de 2012, párr. 135; Corte IDH, Caso Espinoza González vs. Perú, Serie C № 289, sentencia de 20 de noviembre de 2014, párr. 205; Corte IDH, Caso Quispialaya Vilcapoma vs. Perú, Serie C № 308, sentencia de 23 de noviembre de 2015, párr. 117; Corte IDH, Caso Chinchilla Sandoval vs. Guatemala, Serie C № 312, sentencia de 29 de febrero 2016, párr. 168; Corte IDH, Caso Vicky Hernández y otras vs. Honduras, Serie C № 395, sentencia de 26 de marzo de 2021, párrs. 56 y 91.

${ }^{23}$ Corte IDH, Caso Instituto de Reeducación del Menor vs. Paraguay, Serie C № 112, sentencia de 2 de septiembre de 2004, párr. 153; Corte IDH, Caso Lori Berenson Mejía vs. Perú, Serie C № 119, sentencia de 25 de noviembre de 2004, párr. 102; Corte IDH, Caso García Asto y Ramírez Rojas vs. Perú, Serie C № 137, sentencia de 25 de noviembre de 2005, párr. 221; Corte IDH, Caso Yvon Neptune vs. Haití, Serie C № 180, sentencia 6 mayo de 2008, párrs. 181 y 182; Corte IDH, Caso Pacheco Teruel y otros vs. Honduras, Serie C № 241, sentencia de 27 de abril de 2012, párr. 64 .

${ }^{24}$ Para un análisis de las condiciones de existencia digna en la jurisprudencia de la Corte IDH y su relación con la situación de vulnerabilidad y la igualdad material: Beloff; Clerico (2016).
} 
detenidos. Como responsable de los establecimientos de detención, el Estado debe garantizar a los reclusos la existencia de condiciones que dejen a salvo sus derechos". Algo similar sucede cuando, en la nota al pie correspondiente a esta fórmula, Lori Berenson cita el caso Tibi y, sin embargo, allí no se había mencionado la expresión "vida digna”.

\subsection{RELACIÓN DE SUJECIÓN}

Fórmula: Se produce una relación e interacción especial de sujeción entre la persona privada de libertad y el Estado, caracterizada por la particular intensidad con que el Estado puede regular sus derechos y obligaciones y por las circunstancias propias del encierro, en donde al recluso se le impide satisfacer por cuenta propia una serie de necesidades básicas que son esenciales para el desarrollo de una vida digna.

Por su generalidad, la Corte podría invocarla en todas las sentencias referidas a sujetos privados de libertad, pero no lo hace. Aparece por primera vez en el caso Instituto de Reeducación del Menor y es retomada en los casos Montero Aranguren; Fleury; Pacheco Teruel; Mendoza; Chinchilla Sandoval y Hernández ${ }^{25}$. Por su parte, en los casos Caesar y Fermín Ramírez no se hace referencia explícita a la "relación de sujeción", pero la Corte alude a la posición especial del Estado frente a las personas privadas de libertad en virtud del "control o dominio total" que ejercen sobre ellas ${ }^{26}$. Y en Tibi extiende este último concepto de control a otros tipos de custodia, como la que el Estado posee sobre los migrantes ${ }^{27}$.

A partir de esta fórmula, la Corte IDH define el vínculo concreto que une a la persona privada de libertad con el Estado: se trata de una relación de sujeción que parece ser el fundamento de la responsabilidad del Estado siempre que alguna de las necesidades básicas del recluso no sea satisfecha o no lo sea debidamente. Ello es así porque la privación de la libertad implica que el recluso no pueda procurar la satisfacción de sus necesidades básicas por sí mismo. Tal relación peculiar entre el Estado y el detenido implica un acentuado poder del primero sobre las

\footnotetext{
${ }^{25}$ Corte IDH, Caso Instituto de Reeducación del Menor vs. Paraguay, Serie C № 112, sentencia de 2 de septiembre de 2004, párr. 152; Corte IDH, Caso Montero Aranguren y otros (Retén de Catia) vs. Venezuela, Serie C № 150, sentencia de 5 de julio de 2006, párr. 87; Corte IDH, Caso Fleury y otros vs. Haití, Serie C № 236, sentencia 23 de noviembre de 2011, párr. 84; Caso Pacheco Teruel y otros vs. Honduras, Serie C № 241, sentencia de 27 de abril de 2012, párr. 64: Corte IDH, Caso Mendoza y otros vs. Argentina, Serie C № 260, sentencia de 14 de mayo de 2013, párr. 188; Corte IDH, Caso Chinchilla Sandoval vs. Guatemala, Serie C № 312, sentencia de 29 de febrero 2016, párr. 168; y Corte IDH, Caso Vicky Hernández y otras vs. Honduras, Serie C № 395, sentencia de 26 de marzo de 2021 , párr. 56.

${ }^{26}$ Corte IDH, Caso Caesar vs. Trinidad y Tobago, Serie C № 123, sentencia de 11 de marzo de 2005, párr. 97; Corte IDH, Caso Fermín Ramírez vs. Guatemala, Serie C № 126, párr. 118.

${ }^{27}$ Corte IDH, Caso Tibi vs. Ecuador, Serie C № 114, sentencia de 7 de septiembre de 2004, párr. 262.
} 
condiciones de vida del segundo y exige, en consecuencia, que el Estado quede sujeto a un escrutinio estricto sobre cómo utiliza ese poder ${ }^{28}$.

Cabe destacar que esta relación de especial sujeción fue el elemento análogo sobre el cual la Corte fundamentó la aplicación de estándares sobre dignidad de las personas privadas de libertad a otros casos, como el de un recluta del servicio militar ${ }^{29}$. Se volverá sobre ello al analizar los escenarios fácticos que subyacen a las fórmulas.

\subsection{VULNERABILIDAD}

Fórmula: Una persona ilegalmente detenida se encuentra en una situación agravada de vulnerabilidad, de la cual surge un riesgo cierto de que se le vulneren otros derechos, como el derecho a la integridad física y a ser tratada con dignidad.

La sentencia fundacional de esta fórmula es el caso Loayza Tamayo ${ }^{30}$. Allí se revela que la Corte IDH toma de la jurisprudencia del TEDH la noción de vulnerabilidad del detenido. En efecto, en el párrafo 57 de la referida sentencia, la Corte cita el caso Ribitsch v. Austria ${ }^{31}$.

La relación entre dicha vulnerabilidad y el riesgo para la dignidad aparece luego en los casos Niños de la calle, Cantoral Benavídez; Bámaca Velázquez; Juan Humberto Sánchez; Bulacio; Maritza Urrutia; Gómez Paquiyauri; Tibi y López Álvarez 32.

Toda vez que la fórmula se refiere a privación ilegítima de la libertad, muchas de las sentencias que la contienen son casos de desaparición forzada u otros que no corresponden al escenario típico de personas privadas de libertad en establecimientos carcelarios (por ejemplo, en el caso Niños de la Calle, se trataba, precisamente, de niños en situación de calle que fueron secuestrados por fuerzas policiales). De cualquier modo, la Corte también aplica la fórmula en casos de detenidos en establecimientos carcelarios (por ejemplo, en López Álvarez). En

\footnotetext{
${ }^{28}$ Como señala Landa (2002), la dignidad opera gradualmente "sobre la base de la regla democrática: quien tiene más poder está sujeto a mayor control (...) a un mayor respeto de la dignidad, y en consecuencia a una mayor fiscalización del mismo", p. 128. ${ }^{29}$ Corte IDH, Caso Quispialaya Vilcapoma vs. Perú, Serie C № 308, sentencia de 23 de noviembre de 2015, párr. 123.

${ }^{30}$ Corte IDH, Caso Loayza Tamayo vs. Perú, Serie C № 33, sentencia de 17 de septiembre de 1997.

31 TEDH, series A № 336, sentencia del 4 de diciembre de 1995.

32 Corte IDH, Caso de los “Niños de la Calle" (Villagrán Morales y otros) vs. Guatemala, Serie C № 63, sentencia de 19 de noviembre 1999, párr. 166; Corte IDH, Caso Cantoral Benavídez vs. Perú, Serie C № 69, sentencia de 18 de agosto de 2000, párr. 90; Corte IDH, Caso Bámaca Velázquez vs. Guatemala, Serie C № 70, Sentencia de 25 de noviembre de 2000, párr. 150; Corte IDH, Caso Juan Humberto Sánchez vs. Honduras, Serie C № 99, sentencia de 7 de junio de 2003, párr.96; Corte IDH, Caso Bulacio vs. Argentina, Serie C № 100, sentencia de 18 de septiembre de 2003, párr. 127; Corte IDH, Caso Maritza Urrutia vs. Guatemala, Serie C № 103, sentencia de 27 de noviembre de 2003, párr. 87; Corte IDH, Caso Hermanos Gómez Paquiyauri vs. Perú, Serie C № 110, sentencia de 8 de julio de 2004, párr.108; Corte IDH, Caso Tibi vs. Ecuador, Serie C № 114, sentencia de 7 de septiembre de 2004, párr. 147; Corte IDH, Caso López Álvarez vs. Honduras, Serie C № 141, sentencia de 1 de febrero de 2006, párr. 104.
} 
ocasiones, la Corte especifica que la privación que provoca vulnerabilidad puede ser "ilegítima" o "arbitraria".

Se ha señalado que la vulnerabilidad es un "concepto transformador", pretorianamente creado por la Corte IDH, para promover la adopción de medidas especiales de protección a ciertos grupos o personas que se encuentran en una situación específica, como la de los privados de libertad 33 .

\subsection{USO DE LAFUERZA}

Fórmula: Todo uso de la fuerza que no sea estrictamente necesario por el propio comportamiento de la persona detenida constituye un atentado a la dignidad humana en violación del artículo 5 de la Convención Americana.

La fórmula aparece por primera vez en el caso Loayza Tamayo ${ }^{34}$ y la Corte también la toma del TEDH. Al invocarla en el párrafo 57 cita, entre paréntesis, “Ibid., párr. 38”, que se refiere a la cita efectuada en la oración anterior: Ribitsch vs. Austria.

Sin embargo, la segunda vez que la Corte IDH alude a esa fórmula, en el caso Castillo Petruzzi (párr. 197), solo cita Loayza Tamayo y omite la cita originaria del TEDH. Consecuentemente, pareciera que la Corte "hace suya" esa fórmula que ha tomado de su par europeo: lo ha citado la primera vez, pero en todas las invocaciones siguientes que hace de esa fórmula únicamente se cita a sí misma.

Posteriormente, la Corte invoca la fórmula "uso de la fuerza" en los casos Cantoral Benavídez; Bámaca Velázquez; Fleury; Espinoza González y Quispialaya Vilcapoma ${ }^{35}$.

Respecto de esta fórmula, es necesario llamar la atención sobre una posible contradicción en el tribunal. La Corte dice que todo uso de la fuerza será considerado vulneración al artículo 5.2, por primera vez, en el caso Loayza Tamayo y lo reitera en el caso Castillo Pettruzzi. Sin embargo, en los casos Neira Alegría (párrs. 72 y 86) y Durand Ugarte ${ }^{36}$, a pesar de que reconoce que fue

\footnotetext{
33 Burgorgue-Larsen (2014), p. 129 y ss. Sobre las acciones concretas que reclama del Estado esta situación de fragilidad o vulnerabilidad del detenido, véase Castro (2018), p. 43 y ss.

${ }^{34}$ Corte IDH, Caso Loayza Tamayo vs. Perú, Serie C № 33, sentencia de 17 de septiembre de 1997.

${ }_{35}$ Corte IDH, Caso Cantoral Benavídez vs. Perú, Serie C № 69, sentencia de 18 de agosto de 2000, párr. 96; Corte IDH, Caso Bámaca Velázquez vs. Guatemala, Serie C № 70, Sentencia de 25 de noviembre de 2000, párr. 155; Corte IDH, Caso Fleury y otros vs. Haití, Serie C № 236, sentencia 23 de noviembre de 2011, párr. 74; Corte IDH, Caso Espinoza González vs. Perú, Serie C № 289, sentencia de 20 de noviembre de 2014, párr. 184; Corte IDH, Caso Quispialaya Vilcapoma vs. Perú, Serie C № 308, sentencia de 23 de noviembre de 2015, párr. 128.

${ }^{36}$ Corte IDH, Caso Durand y Ugarte vs. Perú, Serie C № 68, sentencia de 16 de agosto de 2000, párr. 79.
} 
desproporcionado el uso de la fuerza de parte de la Marina empleado para detener el motín en el establecimiento carcelario, niega expresamente que esto signifique per se una violación del derecho a la integridad personal en los términos del artículo 5.2. Consecuentemente, no invoca tampoco la fórmula en cuestión, en ninguno de los dos casos.

\subsection{AISLAMIENTO}

Fórmula: El aislamiento prolongado y la incomunicación coactiva son, por sí mismos, tratamientos crueles e inhumanos, lesivos de la integridad psíquica y moral de la persona y del derecho al respeto de la dignidad inherente al ser humano.

La fórmula aparece por primera vez en casos de desaparición forzada, tales como Velázquez Rodríguez, Godínez Cruz y Fairén Garbi37. Luego, desaparecerá de aquella línea jurisprudencial y será receptada en casos de privación de libertad como Castillo Petruzzi (párr. 194); Cantoral Benavídez (párr. 83); Bámaca Velázquez (párr. 150); Maritza Urrutia (párr. 87); De la Cruz Flores (párr. 128); Lori Berenson (párr. 103); Caso del Penal Miguel Castro (párr. 323); Chaparro Álvarez (párr. 171) y Espinoza González (párr. 186)38.

La sentencia fundacional de este criterio de la Corte IDH ha sido, entonces, una de las primeras sentencias de fondo que dictó el tribunal: el caso Velázquez Rodríguez, que contiene la fórmula en el párrafo 156. Seguidamente, la Corte transcribió el artículo 5 de la CADH.

El año siguiente se resolvió el caso Godínez Cruz y se utilizó exactamente el mismo enunciado. Sin embargo, no se citó la sentencia Velázquez Rodríguez. Para ese entonces, la Corte resolvía unas pocas sentencia por año, con lo cual es presumible que tenía presente la única que había dictado el año anterior —Velázquez Rodríguez-y que, además, la repetición exacta del criterio sobre aislamiento e incomunicación no fue casual. Aun así, la transcripción literal carece de cita.

Esto podría insinuar una práctica inicial de la Corte consistente en omitir la citación de sus propios precedentes, a pesar de que se tratase de casos suficientemente análogos y, en especial, a pesar de repetir literalmente el discurso utilizado. Con todo, entiendo que se trata, más bien, de una omisión involuntaria o de un error material, toda vez que la Corte, en Godínez Cruz efectivamente cita precedentes judiciales (aunque del TEDH) y, a su vez, se cita a sí misma en

${ }_{37}$ Corte IDH, Caso Velázquez Rodríguez vs. Honduras, Serie C № 4, sentencia de 29 de julio de 1988, párr. 156; Corte IDH, Caso Godínez Cruz vs. Honduras, Serie C № 5, sentencia de 20 de enero de 1989, párr. 164; Corte IDH, Caso Fairén Garbi y Solís Corrales vs. Honduras, Serie C № 6, sentencia de 15 de marzo de 1989, párr. 149.

${ }^{38}$ Respecto del cambio de criterio de la Corte IDH sobre aislamiento, incomunicación y desaparición forzada, me remito a lo analizado en la sección 3.1 . 
una opinión consultiva ${ }^{39}$. Lo mismo sucede en la sentencia dictada después de Godínez Cruz Fairén Garbi - solo que allí la Corte efectúa, unos párrafos después de utilizar la fórmula sobre aislamiento, una remisión genérica a lo resuelto en los dos casos mencionados, pero sin indicar el párrafo específico referido a dicha fórmula.

Otro error o imprecisión en el uso de esta fórmula es la invocación del caso Suárez Rosero 40 en muchas sentencias, conjuntamente con los casos Velázquez Rodríguez, Godínez Cruz y Fairén Garbi. Lo cierto es que en Suárez Rosero la fórmula no es utilizada: solo se hace mención a la imposibilidad de que el aislamiento se extienda por un prolongado plazo de tiempo, y no se lo relaciona con la dignidad. Justamente, la única mención a la dignidad que se hace en ese fallo es en la transcripción literal del artículo 5.

\subsection{REGLAS MÍNIMAS}

Fórmula: Las Reglas Mínimas de Naciones Unidas para el Tratamiento de Reclusos prescriben las normas básicas respecto al alojamiento, higiene, tratamiento médico y ejercicio de los reos privados de la libertad, a fin de interpretar el contenido del derecho de las personas privadas de libertad a un trato digno y humano.

En ocasiones, la Corte incorpora esta fórmula en el texto principal de su sentencia, mientras que, en otras, directamente cita las Reglas en la nota al pie correspondiente a las fórmulas “condiciones de detención” o "Estado garante", luego de invocar una serie de sentencias. Las Reglas aparecen citadas en Raxcacó; Vélez Loor; Vera Vera; Fleury; Mendoza y Chinchilla Sandoval 41 .

Su incorporación al discurso de la Corte trae consigo más de lo que a simple vista podría parecer. Se trata de un cuerpo normativo muy específico en cuanto a las condiciones de higiene, alojamiento, salud y, en general, condiciones de detención de las personas privadas de libertad. De allí que el hecho de que la Corte efectúe un reenvío a estas Reglas implica que, en una sola oración, incorpora un sinnúmero de "normas básicas", a las que pretende consagrar, cuanto

\footnotetext{
${ }_{39}$ Concretamente cita, en el párrafo 174, la opinión consultiva OC-6/86 del 9 de mayo de 1986, titulada "La expresión "leyes" en el artículo 30 de la Convención Americana sobre Derechos Humanos", Serie A № 6.

${ }^{40}$ Corte IDH, Caso Suárez Rosero vs. Ecuador, Serie C № 35, sentencia de 12 de noviembre de 1997.

${ }^{41}$ Corte IDH, Caso Raxcacó Reyes vs. Guatemala, Serie C № 133, sentencia de 15 de septiembre de 2005, párr. 99 y nota al pie no 66; Corte IDH, Caso Vélez Loor vs. Panamá, Serie C № 218, sentencia 23 de noviembre de 2010, nota al pie no 154; Corte IDH, Caso Vera Vera y otra vs. Ecuador, Serie C № 226, sentencia de 19 de mayo de 2011, párr. 50 y nota al pie no 51; Caso Fleury y otros vs. Haití, Serie C № 236, sentencia 23 de noviembre de 2011, párr. 85; Corte IDH, Caso Mendoza y otros vs. Argentina, Serie C № 260, sentencia 14 de mayo de 2013, párr. 189 y notas al pie no 259, 260; Corte IDH, Caso Chinchilla Sandoval vs. Guatemala, Serie C № 312, sentencia de 29 de febrero 2016, párr. 174 y nota al pie no 252 .
} 
menos, como parámetros interpretativos del trato que merecen las personas privadas de libertad. Asimismo, la manifestación expresa de que allí se encuentran las normas básicas para interpretar "el derecho de las personas privadas de libertad a un trato digno" parece exigir a quien quisiera aplicar el control de convencionalidad sobre las condiciones de detención que se familiarice con ellas ${ }^{42}$. En definitiva, la Corte a través de esta fórmula afirma que aquellas "Reglas Mínimas" son el instrumento básico de interpretación del artículo 5.2 de la CADH.

\subsection{INCOMUNICACIÓN}

Fórmula: La incomunicación durante la detención debe ser excepcional y su uso puede constituir un acto contrario a la dignidad humana.

La excepcionalidad de la incomunicación de un detenido fue invocada, por primera vez, en el caso Suárez Rosero (párrs. 51 y 89), en alusión a la incomunicación que lo privó durante treinta y seis días del contacto con su familia y de la posibilidad de acudir a un abogado. Esta privación de contacto fue el hecho relevante principal y, por ende, casi el único que consideró la Corte para resolver la violación del artículo 5.2 de la CADH. Sin embargo, allí la Corte no utilizó el término “dignidad". Lo mismo sucedió en Castillo Petruzzi (párr. 195) donde la Corte citó en el mismo párrafo las fórmulas “condiciones de detención” y "Estado garante”, y luego simplemente consignó que la incomunicación debe ser excepcional.

Es así que recién se consagra como la fórmula transcripta en el caso Cantoral Benavídez (párr. 82) y es invocada en los casos Bámaca Velázquez (párr. 150); De la Cruz Flores (párr. 127) y Espinoza González (párr. 186). En Chaparro Álvarez (párr. 171), aisladamente, la Corte retoma el reconocimiento de la excepcionalidad de la incomunicación sin mencionar expresamente la dignidad en ese párrafo, tal como lo había hecho en Suárez Rosero y Castillo Petruzzi.

\subsection{FALTA DE ATENCIÓN MÉDICA}

Fórmula: La falta de atención médica adecuada no satisface los requisitos materiales mínimos de un tratamiento digno conforme a la condición de ser humano en el sentido del artículo 5 de la Convención Americana.

\footnotetext{
${ }^{42}$ Por supuesto que es cuestionable cuál es el alcance de esa incorporación que el tribunal hace de soft law a su discurso y en qué medida tales instrumentos (no vinculantes) condicionan el control de convencionalidad. Una postura crítica puede encontrarse en Paúl (2018): "La práctica de la Corte IDH de citar todo tipo de instrumentos ajenos a la CADH, con independencia de que ellos sean vinculantes no aplicables, o no vinculantes, o incluso derecho comparado, soft law e instrumentos privados, da la impresión de que ella desconoce que citar mucho no crea una regla de Derecho", p. 221.
} 
La primera vez que se consigna esta fórmula es en el caso De la Cruz Flores (párr. 131). Luego la repite, en términos exactos, en García Asto (párr. 226) y, curiosamente, no cita De la Cruz Flores. La fórmula aparece también en Montero Aranguren (párr. 102); Vera Vera (párr. 44); Mendoza (párr. 190); Chinchilla Sandoval (párr. 173) y Hernández (párr. 59).

A partir de los casos Montero Aranguren y Vera Vera, la Corte agrega que la violación del artículo 5 se dará dependiendo de "las circunstancias concretas de la persona, tales como el estado de salud o el tipo de dolencia que padece, el lapso transcurrido sin atención, sus efectos físicos y mentales acumulativos". En el caso Chinchilla Sandoval, la Corte relaciona este estándar con la presunción de responsabilidad que recae sobre el Estado frente a la afectación en la salud de un detenido. De modo que la carga probatoria sobre la atención médica debida y el cumplimiento del deber de garante del Estado recae sobre él.

\subsection{INTRODUCCIÓN EN LA MALETERA DE UN VEHÍCULO}

Fórmula: El haber sido introducido en la maletera del vehículo por agentes de Policía es una acción que, por sí sola, debe considerarse claramente contraria al respeto debido a la dignidad inherente al ser humano.

Constituye la fórmula con mayor anclaje fáctico, pues se refiere a una única y precisa conducta que basta para tener por configurada la vulneración a la dignidad de la persona. Esta relación que hace la Corte ha sido calificada como "una visión amplia sobre el vínculo entre dignidad humana e integridad personal" 43 .

Fue invocada, por primera vez, en el caso Castillo Páez (párr. 66), y reiterada en Niños de la Calle (párr. 164) y Bulacio (párr. 109). Cabe destacar que en Niños de la Calle la fórmula se invoca a pesar de que, en los hechos, no se había introducido a los niños dentro de la maletera del vehículo, sino que se los introdujo por la fuerza en este último y se los tuvo secuestrados. De la lectura de los párrafos circundantes a esta cita se desprende que se invoca como una inferencia acerca del sufrimiento psicológico y moral que habrían sufrido las víctimas al permanecer aisladas y “seguramente conscientes de que sus vidas corrían grave peligro”. En esa línea, el que la Corte haya admitido anteriormente que el mero hecho de ser colocado en una maletera es una infracción al artículo 5, "aun cuando no hubieren existido otros maltratos físicos o de otra índole”, parecería habilitar la vulneración a dicho artículo también en este caso. Con todo, es

${ }^{43}$ Nash (2019), p. 162. 
relevante tener en cuenta que aquí la invocación de la fórmula no responde a una identidad entre plataformas fácticas.

\subsection{PRIVACIONES ECONÓMICAS}

Fórmula: Los Estados no pueden invocar privaciones económicas para justificar condiciones de detención que no cumplen con los estándares mínimos internacionales contra tratos y penas crueles, inhumanas y degradantes y que no respetan la dignidad del ser humano.

La sentencia fundacional de la Corte IDH para esta fórmula es el caso Montero Aranguren (párr. 85). Pero allí puede verse que la Corte cita, al utilizarla, dos casos del TEDH: Case of I.I vs. Bulgaria ${ }^{44}$ y Case of Poltoratskiy vs. Ukraine ${ }^{45}$. Una vez más queda en evidencia cómo la Corte se inspira en la jurisprudencia de su par europeo para desarrollar una fórmula que luego adoptará como propia y al hacerlo, en la mayoría de los casos, omitirá la remisión al tribunal original del que emanó.

En efecto, la fórmula se reitera en Boyce; Vélez Loor; Vera Vera; Fleury; Pacheco Teruel; Díaz Peña ${ }^{46}$. Solo en Boyce la Corte seguirá invocando al TEDH en nota al pie, pero a partir de Vélez Loor, se citará únicamente a sí misma. Asimismo, en Boyce la Corte agrega la cita de una comunicación del Comité de Derechos Humanos de las Naciones Unidas ${ }^{47}$.

En cambio, en Vélez Loor citará tan solo Montero Aranguren y Boyce; en Pacheco Teruel, únicamente citará los casos Boyce y Vélez Loor, mientras que, en Díaz Peña, solo citará Montero Aranguren y Vélez Loor. De esta práctica surge que la Corte carece de un criterio uniforme para seleccionar citas.

\footnotetext{
44 TEDH, № 44082/98, sentencia del 9 de junio de 2005.

45 TEDH, № 38812/97, sentencia del 29 de abril de 2003, parr. 148.

${ }^{46}$ Corte IDH, Caso Boyce y otros vs. Barbados, Serie C № 169, sentencia de 20 de noviembre de 2007, párr. 88; Corte IDH, Caso Vélez Loor vs. Panamá, Serie C № 218, sentencia 23 de noviembre de 2010, párr. 198; Corte IDH, Caso Vera Vera y otra vs. Ecuador, Serie C № 226, sentencia de 19 de mayo de 2011, párr. 42; Caso Fleury y otros vs. Haití, Serie C № 236, sentencia 23 de noviembre de 2011, párr. 83; Corte IDH, Caso Pacheco Teruel y otros vs. Honduras, Serie C № 241, sentencia de 27 de abril de 2012, párr. 67, inc. j; Corte IDH, Caso Díaz Peña vs. Venezuela, Serie C № 244, sentencia de 26 de junio de 2012, párr. 135.

47 Comité de Derechos Humanos de las Naciones Unidas, Womah Mukong v. Cameroon, Communication № 458/1991, U.N. Doc. CCPR/C/51/D/458/1991 (1994), párr. 9.3.
} 


\section{Los escenarios fácticos subyacentes}

\subsection{EL ESCENARIO FÁCTICO TíPICO}

El escenario fáctico típico donde tienen aplicación estas fórmulas usuales es el de personas privadas de libertad en establecimientos carcelarios, sometidas a condiciones de detención incompatibles con la dignidad. Esas condiciones se concretan usualmente, como sub-escenarios fácticos, en incomunicación, aislamiento, falta de higiene, de alimentación adecuada y de asistencia médica ${ }^{48}$.

Tal escenario típico ha sido aplicado, analógicamente, por la Corte IDH a: (i) reclutas voluntarios en el servicio militar49; (ii) menores que se encontraban en institutos de reeducación ${ }^{50}$; (iii) una persona sorprendida en robo a quien se alcanzó con un proyectil, fue detenida y no se le prestó debida atención médica51; (iv) migrantes en situación irregular a los que se remitió, ante la falta de albergues migratorios, a establecimientos para detenidos hasta tanto se definiera si serían deportados ${ }^{52}$. La inclusión de todas estas plataformas fácticas se condice con la definición amplia de privación de libertad adoptada por la Comisión Interamericana de Derechos Humanos en los "Principios y buenas prácticas sobre la protección de las personas privadas de la libertad en las Américas" (2008)53.

Es destacable el uso que la Corte IDH hizo de la analogía en el caso del recluta sometido a un trato indigno (Quispialaya Vilcapoma), en el que se detuvo a analizar la aplicación de las fórmulas de dignidad y las citas de otras sentencias en clave de analogía fáctica. Así, frente a un escenario algo distinto al de personas privadas de libertad, pero al que pretendía aplicar el criterio diseñado para aquellas, la Corte consideró necesario justificar tal aplicación de las fórmulas. En

${ }^{48}$ Vale la pena remitirse a la valiosa síntesis de sentencias sobre personas privadas de libertad ef ectuada por Castro, Cillero y Mera (2010).

49 Se trata del caso Quispialaya Vilcapoma. No obstante, es menester destacar que, en el caso Vargas Areco, en el que un niño reclutado en el servicio militar fue torturado y asesinado, la Corte no juzgó las vulne raciones a la dignidad del niño ni utilizó, por ende, las fórmulas relativas al artículo 5.2 de la Convención, debido a que los hechos habían ocurrido con anterioridad a su ratificación por parte de Paraguay. Por ende, solo se juzgó su responsabilidad ulterior por omisión en la investigación de los hechos. 50 Corte IDH, Caso Instituto de Reeducación del Menor vs. Paraguay, Serie C № 112, sentencia de 2 de septiembre de 2004 ; Corte IDH, Caso Mendoza y otros vs. Argentina, Serie C № 260, sentencia del 14 de mayo de 2013.

51 Corte IDH, Caso Vera Vera y otra vs. Ecuador, Serie C № 226, sentencia de 19 de mayo de 2011.

52 Corte IDH, Caso Vélez Loor vs. Panamá, Serie C № 218, sentencia 23 de noviembre de 2010.

53 En efecto, la Disposición general contenida allí establece: “A los efectos del presente documento, se entiende por "privación de libertad': 'Cualquier forma de detención, encarcelamiento, institucionalización, o custodia de una persona, por razones de as istencia humanitaria, tratamiento, tutela, protección, o por delitos e infracciones a la ley, ordenada por o bajo el control de facto de una autoridad judicial o administrativa o cualquier otra autoridad, ya sea en una institución pública o privada, en la cual no pueda disponer de su libertad ambulatoria. Se entiende entre esta categoría de personas, no sólo a las personas privadas de libertad por delitos o por infracciones e incumplimientos a la ley, ya sean éstas procesadas o condenadas, sino también a las personas que están bajo la custodia y la responsabilidad de ciertas instituciones, tales como: hospitales psiquiátricos y otros establecimientos para personas con discapacidades físicas, mentales o sensoriales; instituciones para niños, niñas y adultos mayores; centros para migrantes, refugiados, solicitantes de asilo o refugio, apátridas e indocumentados; y cualquier otra institución similar dest inada a la privación de libertad de personas". 
efecto, las invocó, pero inmediatamente dedicó algunos párrafos a argumentar por qué ellas eran igualmente aplicables como criterios de interpretación a pesar de tratarse de un supuesto diverso al de los detenidos. En el caso, encontró la justificación analógica en el rol del Estado como garante y custodio, en igual medida, tanto de los derechos de los detenidos como de los reclutas.

Por otro lado, la Corte dejó fuera de la aplicación de estas fórmulas otras plataformas fácticas similares como: (i) desaparición forzada y ejecución; (ii) secuestro y desaparición; (iii) falta de diligencia en el debido proceso relativo a detenciones arbitrarias; (iv) persona con discapacidad mental internada en establecimientos de salud mental del sistema público54. En la fundamentación de las sentencias referidas a estos supuestos no hizo uso de las fórmulas usuales que se vienen analizando aquí.

Conviene detenerse brevemente en la relación entre la violación del artículo 5.2, referido a la dignidad, y la desaparición forzada. Al inicio de su jurisprudencia, la Corte IDH desarrolló una presunción de violación de dicho artículo en casos de desaparición forzada ${ }^{55}$. De este modo, en los casos Velázquez Rodríguez, Godínez Cruz y Fairén Garbi consideró violado el artículo 5 por la mera constatación del hecho de la desaparición, aunque no existiera evidencia del menoscabo a la integridad física o a la dignidad. Arribó a tal conclusión a partir del razonamiento según el cual el aislamiento y la incomunicación — condiciones inherentes a la desaparición forzada- bastan para vulnerar la dignidad humana.

Así es que, en este punto, se entrecruzaron las líneas jurisprudenciales en materia de dignidad de personas privadas de libertad y desaparición forzada. Tal como surge del análisis de las fórmulas "aislamiento" e "incomunicación", los primeros casos del escenario fáctico típico —es decir, de personas privadas de libertad-invocan casos de desaparición forzada como Velázquez Rodríguez, Godínez Cruz y Fairén Garbi.

\footnotetext{
${ }^{54}$ En Corte IDH, Caso Ximenes Lopes vs. Brasil, Serie C № 149, sentencia de 4 de julio de 2006, la Corte específicamente se dedicó a analizar los cuidados mínimos y condiciones de internación dignas (párr. 131 y ss.), pero, naturalmente, no aludió a situacio nes de detención, sino a los derechos del paciente y las condiciones de internación. De tal modo, más allá de que en el caso concreto se consideró violado el artículo 5.2 por tratos indignos, uso de la fuerza, condiciones indignas de higiene y alimentación, entre otras, las fórmulas desarrolladas para condiciones de detención no fueron invocadas, con excepción de la de "Estado garante", pues la Corte asimiló la posición especial que tenía el Estado respecto de las personas que están a su cuidado o bajo su custodia (pá rr. 138). Para un análisis detallado del caso, véase Amezcua (2007), pp. 349-351.

${ }^{55}$ Lantrip (1999), p. 555; Santalla (2010), pp. 235-236.
} 
Sin embargo, más adelante, la Corte habría abandonado tal presunción. Así es que en Caballero-Delgado y Paniagua Morales 56 no consideró violado el artículo 5, pues no estaba acreditada la sumisión del desaparecido a torturas u otros malos tratos. Encuadró el caso, en cambio, como violación del derecho a la vida ${ }^{57}$. De tal modo, la Corte abandonó el criterio según el cual la mera configuración de aislamiento e incomunicación propia de la desaparición forzada configura violación del artículo 5.2, y exigió, en cambio, pruebas concretas sobre las condiciones de detención o tratos a los que hubiera sido sometido el desaparecido ${ }^{58}$. En aplicación de este criterio fue que, efectivamente, consideró violado el artículo 5 en el caso Humberto Sánchez, en el que los restos del desaparecido fueron encontrados y se comprobó que había sido sujeto a tratos indignos.

Se ha criticado la distinción que hace la Corte al juzgar la incomunicación y el aislamiento, por un lado, en detenciones ordinarias — casos en los que expresamente encuadra tales condiciones en el artículo 5.2- y, por el otro, en desapariciones forzadas — donde la Corte considera que no bastan para tener por acreditada la vulneración a la dignidad prevista en el artículo 5.259-. Así, Santalla Vargas sostuvo que el giro jurisprudencial era "cuestionable teniendo en cuenta que los casos de desaparición forzada de personas entrañan, necesariamente, incomunicación y aislamiento en la privación (arbitraria) de la libertad física del desaparecido, casos en los que la recolección de evidencia es, por la naturaleza del ilícito, particularmente difícil”60.

Por más que pudiera pensarse que la expresión "privados de libertad" que acuña el artículo 5.2 de la CADH aludiese literalmente a los detenidos en establecimientos carcelarios (es decir, a los detenidos legítimos y no a las detenciones ilegítimas o arbitrarias), lo cierto es que el aislamiento e incomunicación de los detenidos constituyen vulneraciones a su dignidad tal como

\footnotetext{
${ }^{56}$ Corte IDH, Caso Caballero Delgado y Santana vs. Colombia, Serie C № 22, párr. 53 f; Corte IDH, Caso de la "Panel Blanca" (Paniagua Morales y otros) vs. Guatemala, Serie C № 37, sentencia del 8 de marzo de 1998, párr. 89 a.

${ }^{57}$ Santalla (2010) señala que este viraje habría sido influencia del TEDH, especialmente, a partir de la sentencia Kurt contra Turquía (sentencia del 25 de mayo de 1998, § 116), en el que el tribunal se negó a considerar la violación del artículo 3 de la Convención Europea respecto del desaparecido (sí, en cambio, lo hizo respecto de su madre), "al no haberse aportado prueba específica de que este hubiese sido objeto de tortura u otros tratos, ni tampoco respecto a la existencia de una práctica de desaparición forzada tolerada por el gobierno y de tratos inhumanos en detención", p. 236.

${ }^{58}$ Para Bohórquez; Aguirre (2009), la exigencia estricta de pruebas que acrediten la vulneración de la dignidad va en contra de su concepción como inherente al ser humano. Esta última debería generar "presunciones a favor de su potencial vulnerabilidad", p. 54 .

${ }^{59}$ Lantrip (1999), pp. 556-557; Santalla (2010), p. 273. Si bien ambas juristas parecen coincidir en que, en Suárez Rosero, Loayza Tamayo e Hilaire Constantine la Corte aludió a la dignidad para denostar el aislamiento y la incomunicación, en rigor de verdad, los encuadró en la primera oración del artículo 5.2, es decir, los catalogó como tratos crueles, inhumanos o degradantes. Sin embargo, a partir de Castillo Petruzzi, la Corte adoptará la expresión que hemos consignado como fórmula usual "aislamiento", en virtud de la cual lo considera tanto tratos crueles, inhumanos y degradantes como vulneraciones a la dignidad (es decir, lo encuadra en ambas oraciones del 5.2).

${ }^{60}$ Santalla (2010), p. 273.
} 
sucede con el aislamiento e incomunicación de los desaparecidos (extremos que, por su parte, no requieren comprobación, pues son características específicas de las desapariciones forzadas).

La bifurcación entre la línea de dignidad de personas privadas de libertad y la de desaparición forzada se acentuó cuando la Corte comenzó a reconocer a esta última una tipificación autónoma, independiente de los delitos conexos que trajera aparejados. En el caso Goiburú61, la Corte distinguió el delito de desaparición forzada de personas respecto de las violaciones a los derechos a la vida, libertad e integridad personal. Señaló que la desaparición forzada es un delito de lesa humanidad complejo y autónomo, con tipificación propia. Se refirió a él como si se tratase de algo distinto - y algo más - que la violación del derecho a la vida, a la libertad y a la integridad personal (violaciones, estas últimas, que generalmente quedan comprendidas en la configuración de desaparición forzada, pero no la agotan) ${ }^{62}$. De allí que la Corte IDH indicara que “[l]a necesidad de tratar integralmente la desaparición forzada como una forma compleja de violación de derechos humanos, llevan a este Tribunal a analizar en forma conjunta los artículos 4, 5 y 7 de la Convención, en relación con el artículo 1.1..." (párr. 81) y, en el párrafo siguiente, definiera la desaparición forzada de personas como "un hecho ilícito que genera una violación múltiple y continuada de varios derechos protegidos por la Convención Americana y coloca a la víctima en un estado de completa indefensión, acarreando otros delitos conexos". Ese tratamiento como una forma compleja y específica podría ser una razón para que, en la redacción de la sentencia, no aparezcan las fórmulas usuales típicas desarrolladas por la Corte sobre dignidad de los detenidos.

Otra razón por la que las fórmulas no se utilizan en casos de desaparición forzada como Goiburú podría ser que el Estado se había allanado respecto de las violaciones al artículo 5 de la CADH, por lo que había cesado la controversia relativa a los derechos allí consagrados (párr. 49). Lo mismo sucedió en Gutiérrez Soler, donde la Corte dio por violado el artículo 5.2 de la CADH (entre muchos otros), en razón del allanamiento efectuado en ese sentido por el Estado (párrs. 50 y 52) y sin adentrarse en la consideración de los términos de ese artículo ni de la concreción fáctica de su violación en el caso. Eso explica que, en estos supuestos, no se hayan utilizado las fórmulas, a pesar de que la víctima efectivamente hubiera sido sometida a un tratamiento indigno y de que la Corte considerase expresamente violado el artículo 5.2. Consecuentemente,

\footnotetext{
${ }^{61}$ Corte IDH, Caso Goiburú y otros vs. Paraguay, Serie C № 153, sentencia de 22 de septiembre de 2006.

${ }^{6}$ Así es que, por ejemplo, la Corte IDH, en el caso referido, señala que "al allanarse el Estado no se limitó a considerar los hechos como violaciones a los derechos a la vida, libertad e integridad personales, sino que expresamente las calificó como desapari ción forzada de personas de carácter continuado". El "no limitarse" a considerar los hechos como violaciones a derechos individuales, sino que calificarlas como desapariciones continuadas, indica que es algo más.
} 
tampoco estos casos aparecen citados en las múltiples sentencias que se refieren a la dignidad de las personas privadas de libertad.

Finalmente, respecto de la relación entre la dignidad de los detenidos y su derecho a la vida, en los inicios de la jurisprudencia de la Corte se dieron casos de privaciones ordinarias de libertad en los que el tribunal no determinó la violación del artículo 5 por falta de prueba de la vulneración a la dignidad. Allí, la Corte señaló que el hecho de que se hubiera privado de la vida al recluso no indicaba que se hubiera vulnerado el artículo 5.2. Tal fue el razonamiento de la Corte en los casos Gangaram Panday, Neira Alegría y Durand y Ugarte $^{63}$, cuyos hechos involucraban muertes de reclusos y desapariciones de otros a raíz de la sofocación, con un uso desproporcionado de la fuerza, de un motín en un establecimiento carcelario. Dijo la Corte que:

si bien pudiera entenderse que cuando se priva de la vida a una persona también se lesiona su integridad personal, no es este el sentido [del artículo 5] de la Convención que se refiere, en esencia, a que nadie debe ser sometido a torturas, ni a penas o tratos crueles, inhumanos o degradantes, y a que toda persona privada de libertad debe ser tratada con el respeto debido a la dignidad inherente al ser humano.

En ambos casos indicó que no había quedado demostrado que los reclusos hubieran sido "objeto de malos tratos o que se hubiere lesionado su dignidad por parte de las autoridades" durante el tiempo que estuvieron detenidos en el penal. Hay que tener en cuenta, de todos modos, que el criterio de la Corte respecto de la prueba se ha ido flexibilizando, hasta alcanzar, en Isaza Uribe, el estándar según el cual, si una persona bajo custodia estatal ve menoscabado su estado de salud, se presume que la responsabilidad es del Estado a menos que este pruebe lo contrario.

En suma, más allá de las razones que pudieren encontrarse en cada caso concreto, es dable concluir que la violación del artículo 5.2 (y el correlativo uso de las fórmulas referidas a dignidad y privación de la libertad) es analizada por la Corte de modo independiente a: (i) la desaparición forzada; (ii) la violación del derecho a la vida.

\subsection{SUB-ESCENARIOS FÁCTICOS Y ESTÁNDARES}

Lo analizado hasta aquí muestra que el escenario fáctico típico al que las fórmulas están referidas es el de personas privadas de libertad en establecimientos carcelarios. A su vez, ellas se han aplicado, por analogía, a otros tipos de privación de libertad, institucionalización o

${ }^{63}$ Corte IDH, Caso Gangaram Panday vs. Surinam, Serie C № 16, Sentencia de 21 de enero de 1994; Corte IDH, Caso ) Neira Alegría vs. Perú, Serie C № 20, sentencia de 19 de enero de 1995; Corte IDH, Caso Durand y Ugarte vs. Perú, Serie C № 68, sentencia de 16 de agosto de 2000 . 
custodia. El denominador común entre las fórmulas es que tales escenarios son juzgados por la Corte a la luz de la dignidad de esas personas. Sin embargo, una diferencia destacable es que no todas las fórmulas contienen sub-escenarios fácticos concretos, sino que algunas constituyen, más bien, estándares o principios abstractos sobre dignidad de los detenidos. A partir de allí, entonces, es posible clasificarlas del siguiente modo:

(a) Fórmulas con sub-escenarios fácticos determinados: son aquellas que especifican concretamente cuál es la conducta lesiva de la dignidad o cuáles son las exigencias específicas para respetarla. Encuadran en esta categoría las fórmulas "uso de la fuerza"; "aislamiento"; "incomunicación”; “introducción en la maletera de un vehículo”.

(b) Fórmulas sin sub-escenarios fácticos determinados: son aquellas que contienen principios a partir de los cuales interpretar los escenarios fácticos concretos. Encuadran en esta categoría las fórmulas "condiciones de detención”; “Estado garante”; “vida digna”, "privaciones económicas”, "vulnerabilidad”; "Reglas ONU”.

Es preciso señalar, no obstante, que aun cuando las fórmulas que contemplan sub-escenarios concretizan en cierta medida el escenario fáctico general de la privación de libertad, no contienen parámetros específicos de vulneración de la dignidad. Ello es esperable, por cuanto ningún parámetro específico se podrá convertir en una fórmula usual aplicable a una indeterminada cantidad de casos. Más bien, es de suponer que la fórmula contendrá una expresión genérica de la obligación del Estado respecto de cierto marco empírico y que, luego, la Corte aplicará esa generalidad al caso concreto que esté resolviendo.

En cuanto a las "Reglas ONU", si bien la fórmula de la Corte IDH que las contiene es un estándar abstracto, ellas, en sí mismas, son mucho más que eso. Está claro que por su naturaleza normativa y contenido prescriptivo no aluden a ningún escenario fáctico real, sino a escenarios hipotéticos imaginados por sus redactores. No obstante, a diferencia de lo que suele suceder en las normas jurídicas (y, más aún, en los instrumentos internacionales, que normalmente poseen una redacción abstracta y genérica), el contenido normativo de estas Reglas se proyecta sobre circunstancias empíricas muy concretas. En este sentido, se destaca la precisión de las conductas normadas, cuyo anclaje fáctico es mucho más específico que las fórmulas de la Corte (por ejemplo, hasta refieren al tamaño que deben tener las ventanas para que los reclusos lean y trabajen con luz natural). 


\section{Balance sobre el uso de fórmulas}

Seguidamente, se ofrece una serie de reflexiones que se desprenden del examen concreto de las sentencias involucradas, del análisis de las fórmulas y de sus escenarios fácticos:

4.1. El tipo de citas que hace la Corte evidencia una repetición en su discurso y la voluntad expresa de reintroducir ese discurso tal y como se lo ha elaborado anteriormente. Sin embargo, ello no se acompaña con una cita técnicamente adecuada, que reconstruya la línea jurisprudencial cronológica y exhaustivamente, sino más bien se traduce en la cita salpicada de un promedio de dos o tres sentencias que el redactor tiene a mano64.

Por ejemplo, en el caso Lori Berenson, se citan, con relación a la fórmula "condiciones de detención" los mismos casos que son invocados en su precedente inmediato, De la Cruz Flores (así, se invocan los casos Tibi, Instituto de Reeducación del Menor y Bulacio), pero no se cita ese último precedente - De la Cruz Flores - a pesar de que justamente el país contra el cual había recaído sentencia era el mismo (Perú). En cambio, se agrega otro precedente no citado en De la Cruz Flores: Cantoral Benavides. La omisión de citar De la Cruz Flores se arrastra hacia los casos posteriores, en los que la cita de ese precedente también es omitida. Por otra parte, un análisis superficial de la plataforma fáctica de los casos que la Corte elige citar refleja que ellos no poseen mayor analogía con el caso por resolver que la que pudiera existir con aquellos precedentes cuya cita se omite.

Sería más sencilla la visualización de una sentencia como parte del discurso de la Corte y el análisis de la interpretación que ella hace de un artículo de la $\mathrm{CADH}$, si el propio tribunal consignara, al citarse, toda la cadena de citas que sobre ese artículo ha ido construyendo. Debido a que no ha hecho este ejercicio desde un principio, sin duda requerirá mucho trabajo inicial, pero luego se tratará, simplemente, de ir agregando nuevas sentencias a la lista.

4.2. Si bien no se da en todos los casos, el patrón de cita que prevalece es la invocación de la sentencia fundacional y de la sentencia inmediatamente anterior a la que se está dictando (o algunas sentencias cercanas en el tiempo). Aunque aquí también existen inconsistencias: la sentencia fundacional de la primera fórmula, que es Neira Alegría, comienza a ser invocada en el caso inmediatamente posterior a su dictado: Castillo Petruzzi. Y será citada en cuatro casos más.

\footnotetext{
${ }^{64}$ A idéntica conclusión arribó Zavala Achurra, al analizar las citas de la Corte IDH en materia de libertad de expresión. Así, señaló que "la Corte IDH suele citar, cuando habla de las dos dimensiones de la libertad de expresión, los dos casos que aquí hemos señalado, y también todos los casos posteriores que se refieren a este tema. Otras veces cita sólo algunos de estos casos, aun cuando sean varios los que ya han realizado declaraciones virtualmente idénticas". Zavala (2020), p. 13.
} 
Sin embargo, luego desaparece por un lapso (desde Bulacio hasta Boyce), para reaparecer y seguir siendo invocada hasta las últimas sentencias, con intersticios inexplicables o precedentes aislados en los que deja de ser citada (por ejemplo, Espinoza González, Chinchilla Sandoval).

4.3. Las citas consignadas a nota al pie de cada fórmula no están en orden cronológico. Por el contrario, el patrón parece ser, en líneas generales, la cita del caso más reciente primero y los más antiguos después.

4.4. Las citas de la Corte IDH encuadran dentro de la tipología "cita de conceptos comunes"65. En contraposición a lo que sucede con las "citas de analogía”, donde se comparan plataformas fácticas, y la analogía fáctica se transforma en un vínculo de autoridad, las citas de conceptos comunes contienen conceptos jurídicos abstractos que se utilizan como soporte argumental. No obstante, es menester reconocer que subyace, en los casos citados, una analogía fáctica que en ocasiones llega a ser estricta (no meramente permisiva), pues todos se refieren, como se puntualizó oportunamente, a un escenario fáctico común. A pesar de ello, la Corte no utiliza argumentativamente esa analogía fáctica, sino que se limita a la invocación de las fórmulas, como se describirá a continuación.

$\mathrm{Al}$ examinar el texto y contexto que rodea las fórmulas, se comprueba que la práctica de la Corte es invocarlas como marco teórico o hermenéutico de la decisión, para luego analizar el caso concreto y verificar si, en esa situación particular, se produjo una vulneración a la dignidad. Esto lo demuestra el hecho de que las fórmulas son empleadas tanto en casos en los que efectivamente se consigna una lesión a la dignidad (y, en consecuencia, al artículo 5.2) como en los que no. Es decir, que no se trata de citas de una ratio decidendi, o de un precedente, que tienen por objeto seguir la decisión que él hubiera establecido, sino que, más bien, se trata de citas de principios abstractos o estándares de interpretación, que luego son concretizados en el caso específico para extraer las conclusiones que él amerite.

Tal invocación de las fórmulas como marco de análisis para el caso concreto queda en evidencia en el caso Penal Miguel Castro, donde la Corte expresamente, en el párrafo 318, y luego de invocar las fórmulas "Estado garante" y “condiciones de detención”, consigna: "A la luz de los anteriores criterios, y con base en el anexo probatorio del caso, este Tribunal examinará el conjunto de condiciones de detención y de tratamiento a los que fueron sometidos los internos en los centros penales a los que fueron trasladados o reubicados...". Así, puede verse que las

${ }^{65}$ López (2006), pp. 112-117. 
fórmulas son criterios que se complementan con las pruebas obtenidas en cada caso concreto, a la luz de los cuales se examinan las particulares condiciones de detención del caso a resolver. Otro ejemplo de lo mencionado se da en los considerandos 88 y 89 del caso Boyce. El considerando 88 es un cúmulo de fórmulas usuales: la Corte invoca las fórmulas "condiciones de detención" y "privaciones económicas", entre otras expresiones habituales, como la del deber del Estado de salvaguardar "la salud y el bienestar de los reclusos y garantizar que la manera y el método de privación de libertad no exceda el nivel inevitable de sufrimiento inherente a la detención". Acto seguido, en el considerando 89, afirma:

Con base en lo señalado anteriormente, la Corte procederá a analizar las condiciones de prisión en los dos centros de detención en los cuales se encontraban las presuntas víctimas, a saber, la Prisión de Glendairy y la Prisión Temporal de Harrison's Point.

Como se ve, primero fija todos los criterios de interpretación o estándares aplicables al escenario fáctico, para luego dedicarse a analizarlos a la luz del caso concreto. Este esquema se repite, en mayor o menor medida, en todas las sentencias.

No obstante, la Corte no se detiene a analizar comparativamente la aplicación concreta de los estándares comunes en casos pasados. Es decir: (i) invoca el estándar genéricamente formulado; (ii) cita las sentencias anteriores en las que invocó ese mismo estándar genérico; (iii) aplica el estándar o la fórmula en el caso que está resolviendo, pero (iv) no compara esa aplicación con las aplicaciones concretas del estándar en otros casos. En otras palabras, el tribunal no evalúa bajo qué condiciones o circunstancias específicas consideró configurado, en casos pasados, un trato indigno por deficiente alimentación o higiene; más bien, invoca un estándar general de adecuada higiene, para luego pasar a considerar si el caso que tiene ante sí cumple o no con ese estándar. De esta manera, no hay un verdadero enriquecimiento fáctico en la interacción de la Corte consigo misma, sino que hay citas mecánicas de criterios genéricos, lo cual nos lleva al punto siguiente.

4.5. Una reflexión sobre los "puntos nodales" 66 —es decir, aquellas sentencias que son más invocadas, cuyas citas se repiten- muestra que la prevalencia de unas sentencias sobre otras no se da por la riqueza de sus plataformas fácticas, sino, simplemente, por la repetición mecánica de citas por parte del redactor de la sentencia. De otro modo, no podría explicarse por qué la sentencia que más se invoca, en la fórmula “condiciones de detención”, es Neira Alegría cuando, precisamente, en ese caso la Corte no consideró probada la existencia de condiciones indignas

${ }^{66}$ Cfr. López (2006), p. 117. 
de detención ni dio por incumplido el artículo 5.2. En definitiva, es posible advertir que los casos más citados no lo son porque presenten una plataforma fáctica rica para el análisis o comprehensiva de varios hechos que podrían replicarse en el futuro, sino que el criterio de invocación parece estar automatizado siguiendo, como se dijo más arriba, una suerte de patrón por el que se cita la primera sentencia en la que la fórmula aparece y alguna otra que sea más o menos reciente.

4.6. Si la Corte fuera citando, a medida que utiliza cada fórmula, todos aquellos casos en los que la empleó, dejaría expuesta la consistencia que mantiene en el discurso respecto de la interpretación de un artículo de la CADH. Al no hacerlo, deja ver que le resulta indiferente explicitar desde cuándo aplica el criterio o que se trata de una doctrina consolidada o reiterada (es decir, que ha sido un criterio repetido por ella misma a lo largo de toda su jurisprudencia). De ello se deduce que la invocación de sus precedentes tiene una finalidad meramente ilustrativa, en el sentido de que se limita a brindar ejemplos en los que la Corte ha sostenido lo mismo ${ }^{67}$. Esto que podría parecer, a simple vista, un modo aceptable de citarse a sí misma, complejiza, sin embargo, el control de convencionalidad que el tribunal pretende de todos los funcionarios de los Estados parte de la $\mathrm{CADH}$, quienes deberían efectuar un verdadero trabajo de investigación — similar al que aquí se ha realizado - si quisieran identificar todas las sentencias donde la Corte hubiese fijado su criterio o interpretado un artículo en particular de la Convención ${ }^{68}$. Está claro que ella no lo hace por sí misma al citarse ${ }^{69}$.

\section{Conclusiones}

La investigación efectuada permite extraer las siguientes conclusiones:

5.1. La metodología de invocación y uso de sus propias sentencias por parte de la Corte IDH en materia de dignidad de personas privadas de libertad se caracteriza por la repetición de fórmulas usuales.

\footnotetext{
${ }^{67}$ Habitualmente, el precedente ilustrativo o persuasivo se opone al vinculante. En materia de privación de libertad, en tanto la Corte no ha oscilado demasiado en su jurisprudencia (más bien tiende a ser lineal), no puede constatarse si aquella dota o no a su precedente de vinculatoriedad.

${ }^{68}$ Adviértase que el propio presidente de la Corte IDH, en un artículo doctrinario, menciona esta línea jurisprudencial sobre las condiciones de detención y solamente cita en nota al pie dos sentencias: los casos Tibi y Caesar (que, por lo demás, no constituyen ni el leading case en la materia ni los últimos casos en que la fórmula fue utilizada). Ferrer MacGregor (2014), p. 36, nota al pie no 15.

${ }^{69}$ Gran parte de este vacío viene suplido, en lo que hace a la interpretación de la dignidad, por la base de datos desarrollada en el proyecto de investigación del que forma parte este artículo, de inminente publicación. A su vez, la Corte IDH produce cuadernos de jurisprudencia que pueden ser útiles para consignar parámetros que ha establecido sobre una materia determinada.
} 
5.2. La jurisprudencia del TEDH ha servido de inspiración a la Corte IDH para el desarrollo de varios de esos estándares y fórmulas usuales, que la Corte adopta como propios a tal punto que, paulatinamente, abandona la cita del tribunal regional europeo.

5.3. El escenario típico de aplicación de estas fórmulas es el de vulneración de la dignidad de personas privadas de libertad en establecimientos carcelarios. Analógicamente, la Corte ha aplicado los mismos estándares a reclutas en el servicio militar, a adolescentes en establecimientos de reeducación y a migrantes ilegales. En cambio, las fórmulas no suelen ser aplicadas en casos de desaparición forzada.

5.4. Algunas de estas fórmulas contienen un sustrato o sub-escenario fáctico individualizado, mientras que otras constituyen principios o estándares hermenéuticos abstractos.

5.5. La incorporación de estas fórmulas al discurso de la Corte ostenta ciertas imperfecciones e inconsistencias, entre las que se destaca la omisión de reconstruir en la cita toda la línea jurisprudencial. Se opta, en cambio, por una elección arbitraria (y aleatoria) de dos o tres casos en los que la fórmula hubiera sido utilizada.

5.6. Dentro de la referida aleatoriedad, se distingue un patrón de invocación de las propias sentencias, que consiste en citar la más reciente y, en muchos casos, invocar también la sentencia fundacional.

5.7. Las fórmulas reflejan el entrecruzamiento que la Corte propone (y aplica) entre el respeto a la dignidad y las condiciones carcelarias, que puede resumirse en torno a cuatro ejes centrales: las personas privadas de libertad tienen derecho a vivir en condiciones dignas de detención y a que se garantice su vida, su integridad personal, su bienestar y su salud; el Estado es garante del respeto de los derechos de los detenidos, porque están bajo su custodia; el Estado no puede invocar motivos de índole económica para excluirse del cumplimiento de los estándares mínimos de detención; hay ciertas condiciones de detención, como el aislamiento prolongado, la incomunicación o el uso excesivo de la fuerza, que son en sí mismos lesivos de la dignidad y generan responsabilidad del Estado. 


\section{Bibliografía citada}

Acosta López, Juana Inés; Amaya Villarreal, Álvaro Francisco (2011): “La responsabilidad internacional del Estado frente al deber de custodia: estándares internacionales frente a los centros estatales de detención”, en Revista Estudios Socio-Jurídicos (Vol. 13, N. 2), pp. 301326.

Amezcua, Luis (2007): "Algunos puntos relevantes sobre la dignidad humana en la jurisprudencia de la Corte Interamericana de Derechos Humanos", en Revista Iberoamericana de Derecho Procesal Constitucional (N. ) 8), pp. 339-355.

Beloff, Mary; Clérico, Laura (2016): “Derecho a condiciones de existencia digna y situación de vulnerabilidad en la jurisprudencia de la Corte Interamericana", en Estudios Constitucionales (Año 14, N. 1), pp. 139-178.

Burgorgue-Larsen, Laurence (2014): “El contexto, las técnicas y las consecuencias de la interpretación de la Convención Americana de los Derechos Humanos", en Estudios Constitucionales (Año 12, N. 1), pp. 105-161.

Bohórquez Monsalve, Viviana; Aguirre Román, Javier (2009): “Las tensiones de la dignidad humana: conceptualización y aplicación en el derecho internacional de los derechos humanos”, en Sur. Revista Internacional de Derechos Humanos (Vol. 6, N. 11), pp. 41-63.

Carozza, Paolo (2003): "My Friend is a Stranger: The Death Penalty and the Global Ius Commune of Human Rights”, en Texas Law Review (Vol. 81, N. ㄴ 4), pp. 1031-1089.

Castro, Álvaro; Cillero, Miguel; Mera, Jorge (2010): Derechos fundamentales de los privados de libertad. Guía práctica con los estándares internacionales en la materia (Santiago, Andrea Palet editora).

Castro Morales, Álvaro Esteban (2018): “Estándares de la Corte Interamericana de Derechos Humanos en materia de imputados y condenados privados de libertad", en Anuario de Derechos Humanos (N. $\left.{ }^{14}\right)$, pp. 35-54.

Comisión Interamericana de Derechos Humanos (2008): “Principios y buenas prácticas sobre la protección de las personas privadas de la libertad en las Américas". 
Corte Interamericana de Derechos Humanos y Cooperación Alemana (2020). “Cuadernillo de Jurisprudencia de la Corte Interamericana de Derechos Humanos N. ㅇ: Personas privadas de libertad. [Disponible en https://bit.ly/3jqyPOS]. [Fecha de consulta: 5 de octubre de 2020].

Escobar Gil, Rodrigo (2013): “Discurso del Relator sobre los Derechos de las personas privadas de libertad de la Comisión Interamericana de Derechos Humanos”, en Revista Internacional de Derechos Humanos (Año III, N. ㅇ 3), pp. 45-53.

Ferrer MacGregor, Eduardo (2014): “Las siete principales líneas jurisprudenciales de la Corte Interamericana de Derechos Humanos aplicable a la justicia penal”, en Revista IIDH, (N. 59), pp. 29-118.

Girón Unigarro, Lucy (2018): “Dignidad humana e integridad de las personas privadas de la libertad a la luz del paradigma de la Corte Interamericana de Derechos Humanos", en Cuadernos de Derecho Penal, pp. 159-188.

Glendon, Mary Ann (2012): “La soportable levedad de la dignidad”, en Persona y Derecho (Vol. 67, N.ㅇ 2), pp. 253-262.

Landa, César (2002): “Dignidad de la persona humana”, en Cuestiones Constitucionales (․o 7), pp. 109-138.

Lantrip, Julie (1999): “Torture and Cruel, Inhumane and Degrading Treatment in the Jurisprudence of the Inter-American Court of Human Rights", en ILSA Journal of Internacional \& Comparative Law (Vol. 5, N. 3), pp. 551-566.

López Medina, Diego E. (2006): El Derecho de los jueces: Obligatoriedad del precedente constitucional, análisis de sentencias y líneas jurisprudenciales y teoría del derecho judicial (Bogotá, Legis, 2ª ed.).

McCrudden, Christopher (2008): "Human Dignity and Judicial Interpretation of Human Rights", en The European Journal of International Law (Vol. 19, N. 4), pp. 655-724

Nash Rojas, Carlos (2019): “Artículo 5. Derecho a la integridad personal”, en Steiner, Christian; Fuchs, Marie-Christine (eds.), Convención Americana sobre Derechos Humanos. Comentario (Bogotá: Nomos impresores, $2^{\underline{a}}$ ed.). 
Paúl, Álvaro (2018): “Cuatro extendidos desaciertos de la Corte Interamericana que se observan en su opinión consultiva N. 24", en Anuario de Derecho Público (Santiago, Editorial Universidad Diego Portales), pp. 203-226.

Ratti Mendaña, Florencia S. (2021): “El discurso de la Corte Interamericana de Derechos Humanos sobre dignidad de personas privadas de libertad: fuentes, citas y fórmulas usuales", en Revista de la Facultad de Derecho, en prensa.

Santalla Vargas, Elizabeth (2010): "La múltiple faceta de la tortura y los "otros tratos" en la jurisprudencia de la Corte Interamericana de Derechos Humanos y de los Tribunales Penales Internacionales" en AAVV, Sistema interamericano de protección de los derechos humanos y derecho penal internacional (Montevideo, Fundación Konrad Adenauer Stiftung), vol. 1, pp. 229-262.

\section{Jurisprudencia}

Corte IDH: Velásquez Rodríguez vs. Honduras, Fondo, sentencia del 29 de julio de 1988, serie C N. .9 .

Corte IDH: Godínez Cruz vs. Honduras, Fondo, sentencia del 20 de enero de 1989, serie C N. 5.

Corte IDH: Fairén Garbi y Solís Corrales vs. Honduras, Fondo, sentencia del 15 de marzo de 1989, serie C N. $\stackrel{0}{6}$.

Corte IDH: Gangaram Panday vs. Suniram, Fondo, Reparaciones y Costas, sentencia del 21 de enero de 1994, serie C N. 16 .

Corte IDH: Neira Alegría y otros vs. Perú, Fondo, sentencia del 19 de enero de 1995, serie C N. 20.

Corte IDH: Loayza Tamayo vs. Perú, Fondo, sentencia del 17 de septiembre de 1997, serie C N.o 33.

Corte IDH: Castillo Páez vs. Perú, Fondo, sentencia del 3 de noviembre de 1997, serie C N. 34 .

Corte IDH: Suárez Rosero vs. Ecuador, Fondo, sentencia del 12 de noviembre de 1997, serie C N. 035 . 
Corte IDH: Caso de la "Panel Blanca" (Paniagua Morales y otros) vs. Guatemala, Fondo, sentencia del 8 de marzo de 1998, serie C N. 37 .

Corte IDH: Castillo Petruzzi y otros vs. Perú, Fondo, Reparaciones y Costas, sentencia del 30 de mayo de 1999, serie C N. 52 .

Corte IDH: Villagrán Morales y otros ("Niños de la Calle") vs. Guatemala, Fondo, sentencia del 19 de noviembre de 1999, serie C N. 63.

Corte IDH: Durand Ugarte vs. Perú, Fondo, sentencia del 16 de agosto de 2000, serie C N. 68.

Corte IDH: Cantoral Benavides vs. Perú, Fondo, sentencia del 18 de agosto de 2000, serie C N. 69.

Corte IDH: Bámaca Velásquez vs. Guatemala, Fondo, sentencia del 25 de noviembre de 2000, serie C N.웅. 70 .

Corte IDH: Hilaire, Constantine y Benjamín y otros vs. Trinidad y Tobago, Fondo, Reparaciones y Costas, sentencia del 21 de junio de 2002, serie C n. o 94.

Corte IDH: Juan Humberto Sánchez vs. Honduras, Excepción Preliminar, Fondo, Reparaciones y Costas, sentencia del 7 de junio de 2003, serie C N.o 99.

Corte IDH: Bulacio vs. Argentina, Fondo, Reparaciones y Costas, sentencia del 18 de septiembre de 2003 , serie C N. 100 .

Corte IDH: Maritza Urrutia vs. Guatemala, Fondo, Reparaciones y Costas, sentencia del 27 de noviembre de 2003, serie C N. 103.

Corte IDH: Caso de los Hermanos Gómez Paquiyauri vs. Perú, Fondo, Reparaciones y Costas, sentencia del 8 de julio de 2004, serie C N. 110 .

Corte IDH: Instituto de Reeducación del Menor vs. Paraguay, Excepciones Preliminares, Fondo, Reparaciones y Costas, sentencia del 2 de septiembre de 2004, serie C N. 112 .

Corte IDH: Tibi vs. Ecuador. Excepciones Preliminares, Fondo, Reparaciones y Costas, sentencia del 7 de septiembre de 2004. Serie C N. 114. 
Corte IDH: De la Cruz Flores vs. Perú. Fondo, Reparaciones y Costas, sentencia del 18 de noviembre de 2004, serie C N. 115 .

Corte IDH: Lori Berenson Mejía vs. Perú, Fondo, Reparaciones y Costas, sentencia del 25 de noviembre de 2004, serie C ‥ 119.

Corte IDH: Caesar vs. Trinidad y Tobago, Fondo, Reparaciones y Costas, sentencia del 11 de marzo 2005, serie C N.운. 123.

Corte IDH: Fermín Ramírez vs. Guatemala, Fondo, Reparaciones y Costas, sentencia del 20 de junio de 2005, serie C N. 126.

Corte IDH: Raxcacó Reyes vs. Guatemala, Fondo, Reparaciones y Costas, sentencia del 15 de septiembre de 2005, serie C N. 133.

Corte IDH: García Asto y Ramírez Rojas vs. Perú, sentencia del 25 de noviembre de 2005, serie C N.o 137.

Corte IDH: López Álvarez vs. Honduras, Fondo, Reparaciones y Costas, sentencia del 1 de febrero de 2006, serie C N. 141 .

Corte IDH: Ximenes Lopes vs. Brasil, sentencia del 4 de julio de 2006, serie C N. 149

Corte IDH: Montero Aranguren y otros (Retén de Catia) vs. Venezuela, sentencia del 5 de julio de 2006, serie C N. 150 .

Corte IDH: Goiburú y otros vs. Paraguay, Fondo, Reparaciones y Costas, sentencia del 22 de septiembre de 2006, serie C N. 153 .

Corte IDH: Caso del Penal Miguel Castro Castro vs. Perú, Fondo, Reparaciones y Costas, sentencia del 25 de noviembre de 2006, serie C N. 160 .

Corte IDH: Boyce y otros vs. Barbados, Excepción Preliminar, Fondo, Reparaciones y Costas, sentencia del 20 de noviembre de 2007, serie C N.o 169 .

Corte IDH: Chaparro Álvarez y Lapo Íñiguez vs. Ecuador, Excepciones Preliminares, Fondo, Reparaciones y Costas, sentencia del 21 de noviembre de 2007, serie C N. 170 . 
Corte IDH: Yvon Neptune vs. Haití, Fondo, Reparaciones y Costas, sentencia del 6 de mayo de 2008, serie C N. 180 .

Corte IDH: Vélez Loor vs. Panamá. Excepciones Preliminares, Fondo, Reparaciones y Costas, sentencia del 23 de noviembre de 2010, serie C N. 218.

Corte IDH: Vera Vera y otra vs. Ecuador, Excepción Preliminar, Fondo, Reparaciones y Costas, sentencia del 19 de mayo de 2011, serie C N. 226.

Corte IDH: Fleury y otros vs. Haití. Fondo y Reparaciones, sentencia de 23 de noviembre de 2011, serie C N. 236 .

Corte IDH: Pacheco Teruel y otros vs. Honduras, Fondo, Reparaciones y Costas, sentencia del 27 de abril de 2012, serie C N. 241 .

Corte IDH: Díaz Peña vs. Venezuela, Excepción Preliminar, Fondo, Reparaciones y Costas, sentencia del 26 de junio de 2012, serie C N. 244.

Corte IDH: Mendoza y otros vs. Argentina, Excepciones Preliminares, Fondo y Reparaciones, sentencia del 14 de mayo de 2013, serie C N.ㅇ 260.

Corte IDH: Espinoza Gonzáles vs. Perú, Excepciones Preliminares, Fondo, Reparaciones y Costas, sentencia del 20 de noviembre de 2014, serie C N. 289.

Corte IDH: Quispialaya Vilcapoma vs. Perú, Excepciones Preliminares, Fondo, Reparaciones y Costas, sentencia de 23 de noviembre de 2015, serie C N. 308.

Corte IDH: Chinchilla Sandoval vs. Guatemala, Excepción Preliminar, Fondo, Reparaciones y Costas, sentencia de 29 de febrero de 2016, serie C N. 312 .

Corte IDH: Isaza Uribe y otros vs. Colombia, Fondo, Reparaciones y Costas, sentencia del 20 de noviembre de 2018, serie C N. $\stackrel{0}{363}$.

Corte IDH: Hernández vs. Argentina, Excepción Preliminar, Fondo, Reparaciones y Costas, sentencia del 22 de noviembre de 2019, serie C N. 395 .

TEDH: Ribitsch v. Austria, Judgment of 4 December 1995, Series A N. 336 
TEDH: Kudla v. Polonia, No. 30210/96, Sentencia de 26 de octubre de 2000, Reports 2000 XI

TEDH: I. I. v. Bulgaria Sentencia del 9 de junio de 2005. Application N. ${ }^{\text {44 4082/98 }}$

TEDH: Poltoratskiy v. Ukraine, sentencia del 29 de abril de 2003, Application N. 38812/97 